\title{
Tire Pressure Monitoring System Using SoC and Low Power Design
}

\author{
A. Vasantharaj1, K. Krishnamoorthy² \\ ${ }^{1}$ Department of ECE, Excel Engineering College, Namakkal, India \\ ${ }^{2}$ Department of CSE, Shanmughanathan Engineering College, Pudukottai, India \\ Email:vasanthraj_a@yahoo.co.in,kkr_510@yahoo.co.in
}

How to cite this paper: Vasantharaj, A. and Krishnamoorthy, K. (2016) Tire Pressure Monitoring System Using SoC and Low Power Design. Circuits and Systems, 7, 4085-4097.

http://dx.doi.org/10.4236/cs.2016.713337

Received: May 2, 2016

Accepted: May 20, 2016

Published: November 11, 2016

Copyright $\odot 2016$ by authors and Scientific Research Publishing Inc. This work is licensed under the Creative Commons Attribution International License (CC BY 4.0).

http://creativecommons.org/licenses/by/4.0/ (c) (i) Open Access

\begin{abstract}
This paper presents the tire pressure monitoring system (TPMS) by using the system on chip (SoC) mixed signals with the help of Bluetooth transmission and in advantage of low power consumption design. This is to monitor the variations in temperature and pressure of the vehicle's tire, and the TPMS system is involved. It improves the driver's safety by automatically detecting the tire pressure and temperature and then warning signal is sent to driver to take a measure, which prevents from accident. The proposed system of tire pressure monitoring system using SoC increases the speed of indication time to the driver by using mixed signals. The inflation of the tire can be avoided by preventing from high temperature and high pressure. Limitation of temperature and pressure in the previous system is also elongated i.e. temperature from $-40^{\circ} \mathrm{C}$ to $125^{\circ} \mathrm{C}$ and pressure from 0 to $750 \mathrm{Kpa}$. Sensors, wireless communication (Bluetooth dongle) and SoC unit are used to design the low power TPMS. Quantitative results are taken and the analogy between temperature and pressure is also verified. The tested results proved by need of the practical system. Signal conditioning voltage and $\mathrm{SoC}$ unit is the trace for low power design TPMS. Finally, the performance of the system is tested and executed by using proteus software given as a real time application.
\end{abstract}

\section{Keywords}

Wireless Communication, System on Chip (SoC), Tire Pressure Monitoring System (TPMS), Bluetooth Dongle, Pressure and Temperature Sensors

\section{Introduction}

One of the main reasons for serious traffic accidents is bursting or inflation of tires. Hence the number of traffic accidents is also increasing along with the rapid growth in 
number of vehicles, due to this cause human life gets wasted. Tire bursting is main concern for the drivers since prediction is very difficult. Tire burst is mainly caused by abnormal tire pressure and higher tire temperature. Thus traffic accidents can be prevented if the tire pressure is regularly monitored during driving [1].

Many new high-end vehicles list tire pressure monitoring as part of standard equipment. In the past this was typically achieved by enhancing the capabilities of the Antilock Braking System (ABS) using differential (wheel-to-wheel) rotational speed measurement as a criteria to check if one tire was under inflated [2]. The accuracy and response time of this type of system unfortunately was not high enough to satisfy legislation requirements. It was also incapable of providing a reliable warning if all the tires were under inflated as it relied on a differential measurement. On such systems, user intervention was required to reset the system after any tire maintenance period.

The circuit solution shown in below is based on a system that monitors pressure, motion, temperature, and battery voltage at each tire (see above). This information is processed and data are transmitted from each wheel to the vehicle's central controller where, if necessary, the driver is warned of an unsafe condition. The information provided to the driver can be as simple as an alarm or as complex as a dashboard digital display of each individual tire's pressure. Some systems may also include the capability of a requested read back or Pressure On Demand (POD) [3].

Therefore the abnormal tire pressure affects the quality and the safety of automobile driving. A research study shows if the tire pressure is maintained near to its standard value and pressure changes are discovered within time, the possibility of tire-break can be avoided. Thus many engineers and researchers are still working on Tire Pressure Monitoring System (TPMS) [4].

TPMS can be divided into two types: 1) it is based on the wheel speed also called as indirect TPMS; 2) some TPMS wheel sensors transmit adverse pressure conditions immediately; others that power off when parked only wake-up after the vehicle has achieved a minimum speed (usually $15 \mathrm{mph}$ ). For the racing specialist, RS232 links are available to enable conditions to be sent via computer telemetry to the pit [5] [6] [7] [8] [9]. The receiver/display typically requires either a $12 \mathrm{v}$ or $24 \mathrm{v}$ DC supply, usually switched with the ignition. Options include combined Display and Receiver, or separate Display Module and Receiver Module with interconnecting cord [10] [11].

In direct TPMS, the difference between the speeds of the tires is compared through an Antilock Braking System (ABS) wheel speed sensor system [12]. The disadvantage of this system is that it cannot able to work if vehicle is moving with a speed above $100 \mathrm{~km}$ or if two tires are under-inflated. So this system works only when the wheels speed is up to a certain range [8]. The next one is based on the pressure sensor, and it's called as direct-TPMS. This system makes use of pressure and temperature sensor which are installed in each tire; this will directly measure the tire's pressure and temperature, then it displays the monitored level in each tire [10]. This also indicates the buzzer sound when the temperature and pressure goes to maximum level. In TPMS the battery can't be replaced effectively, so we proposed the enhanced low power design. According to the Ac- 
countability Transportation, Documentation and Recall Enhancement (TREAD) Act passed by US Congress in 2008, it is necessary for all automobile manufacturers company to install this tire pressure monitoring system in all vehicles which are previously sold or being produced in the United States [9]. The structure of TPMS is shown in Figure 1.

The significant of running the tires at the specified pressure level will helps to provide proper vehicle handling while avoiding premature tire wear. The right pressure for a vehicle is well-stated on the tire information label or inside the glove-box door. The label also lists high load and tire size (including spare). Also, the tires flex excessively which produces more rapid wear and extra heat. The centre of the tread to wear is caused due to over inflation [1]. There is no normal flex in tires so this puts stress on the plies and sidewalls. The tire pressure monitoring systems (TPMS) based on Bluetooth or wireless technology discussed here can also be used in wide range of applications.

\section{System on Chip}

All components or other electronic systems that are integrated into a single chip are called as System on a Chip (SoC). The single chip substrate may that contain analog, digital or mixed-signal and often RF frequency function. Due to low power consumption of SoC, it is very commonly used in mobile electronics. Embedded system is one of the major applications of this SoC.

Integrated Circuits (ICs) are normally divided into digital or analog circuits such as (i.e., microprocessors) or (i.e., operational amplifiers). The IC's with mixed-signal are the chips which contains both analog and digital circuits on a single chip. The chips in this category are mostly used in the $3 \mathrm{G}$ cell phones and technologies with the portable devices like in PC.

The digital devices frequently use the mixed-signal ICs since it converts analog signals to digital signals and digital signals to analog signals. For example, in FM tuners the mixed-signal ICs are one of the essential components and digital amplifiers is also an essential component for digital products like media player. The analog signal (such as, a light wave, a sound or FM radio transmission) can be digitized using an analogto-digital converter, such wise mixed signal IC's are the smallest and energy efficient as in the form of recent technologies. The technologies power over Ethernet also often

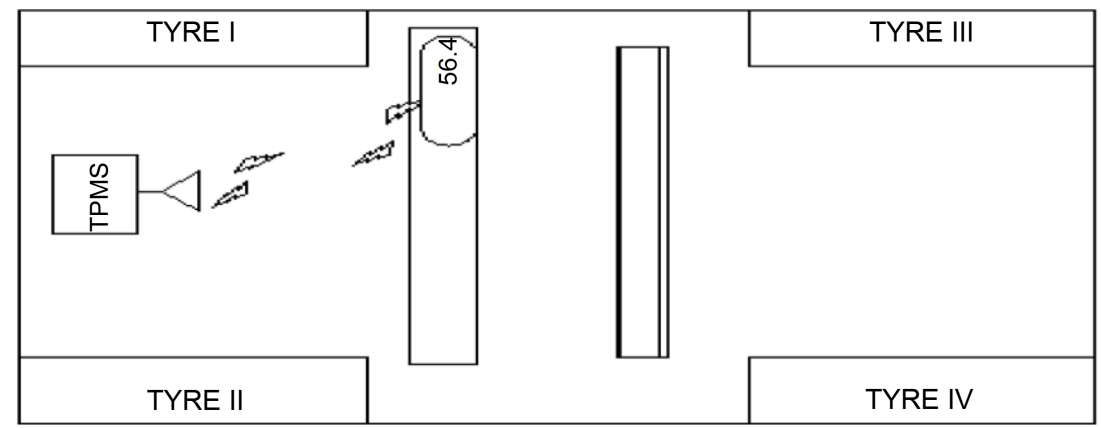

Figure 1. General TPMS attached in vehicle. 
uses the mixed signal ICs. The analog power "signal", is transmitted alongside a digital data signal (Ethernet) over the same wire where mixed-signal ICs allow this technology. The manufacturing and designing of Mixed-signal ICs are more difficult than digital-only or analog-only integrated circuits. A common power supply is used for both digital and analog components for an efficient mixed-signal IC.

\section{Experimental Setup of TPMS Using SoC}

Power management is considered to be one of the main aspect in designing battery operated Tire Pressure Monitoring Systems (TPMS) as it helps to prolong the lifespan of the battery. There are so many methods that can be used to design a low power tire-pressure and service monitoring system. One of the most prominent methods for power reduction is the duty cycle method. This suggests an idea of implementing the TPMS in combination with a separate Bluetooth circuit, especially a very low power (active or passive) RFID whose sole purpose is to detect the interrogating signal [13].

In the experimental setup the TPMS can be designed with the help of low power PIC or DSP integrated microcontroller, the sensors like temperature and pressure sensors which might produce an analog value. And it is given as a input to the processor or controller through an A/D converter. As we know that the power management has been connected with the ignition of the vehicle, the power consumption is achieved.

SoC unit which utilizes only less wires as proportional the speed of the indication time is fast. SPI interface is an another advantage which helps to speed up the indication time whereas the SPI interface consists of MOSI, MISO, SCLK and SS. SPI interface has many application for short distance communication. The experimental setup of TPMS is shown in Figure 2.

The resistance value can be calculated with the help of wheat stone bridge,

$$
\frac{P}{R_{4}}=\frac{R_{2}}{R_{3}}
$$

where,

$$
P=\frac{R_{2} R_{4}}{R_{3}}
$$

TPMS block diagram for transmitter and receiver is shown in Figure 3 and Figure 4. In the distribution, service and monitoring of tires it is vital to be able to identify a tire, to measure its parameters (pressure, temperature, etc.) and to maintain a record of service.

\subsection{Working Principle}

The transmitter part is fixed inside the tires of car. It consists of pressure sensor, temperature sensor and microcontroller unit. The pressure sensor will measure the tire pressure and temperature by the temperature sensor. The measured temperature and pressure from the sensors are transmitted to the microcontroller. And the controller is previously programmed to monitor the level of pressure and temperature of tire. Then 


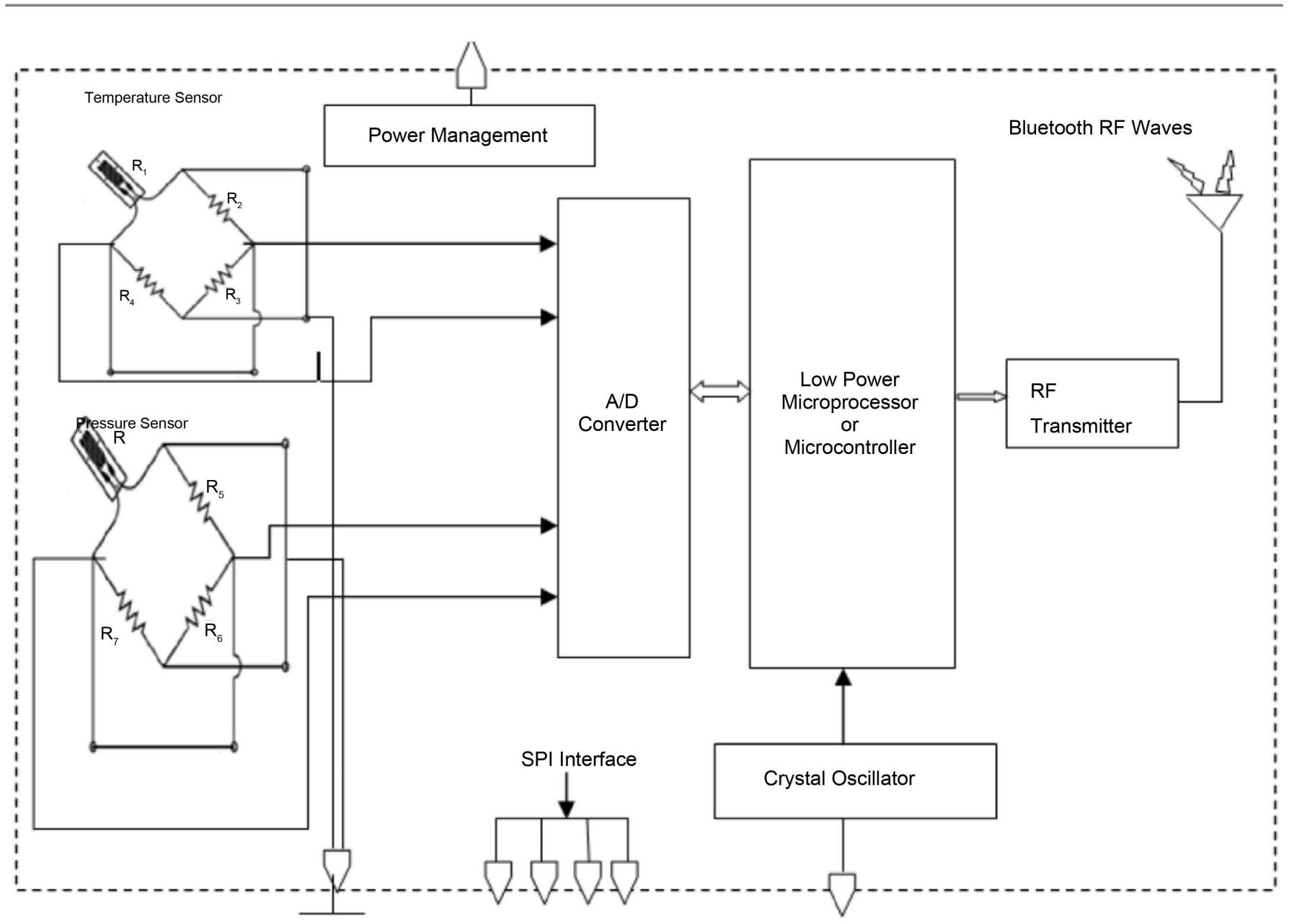

Figure 2. Hardware design block diagram of TPMS transmitter.

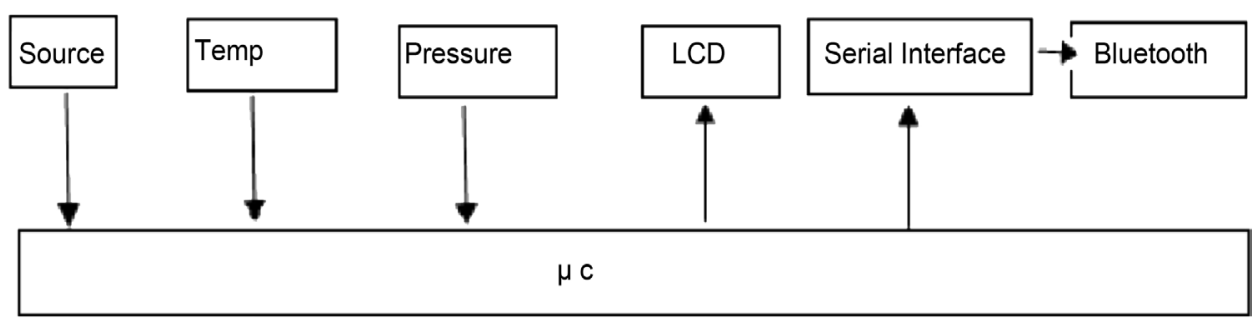

Figure 3. Transmitter side.

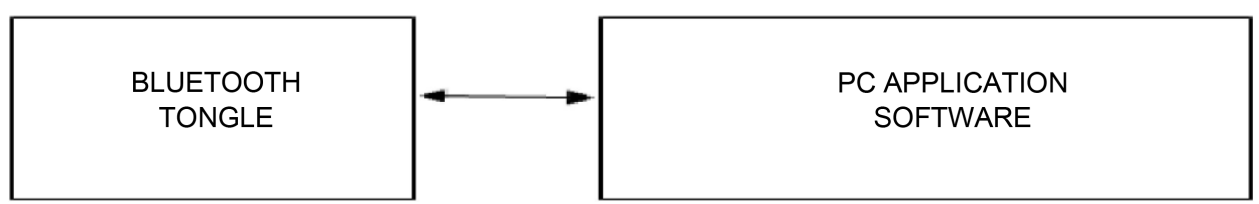

Figure 4. Receiver side.

the monitored signal is transmitted to the receiver block through the SoC unit. The mixed signal SoC unit have the ability which itself converts the digital signal to analog and vice versa to transmit the signal to the receiver side of the system through the Blu- 
etooth modem.

Then the signal is displayed in the receiver side of the PC software developed for the indication of measurement. When the signal is received from the tire of the car through the SoC unit it sent to the MCU. If the temperature or pressure is high or low, it will be displayed through LCD display module. Then the driver can control the car by applying manual brake system.

\subsection{Microcontroller, Warning System \& Sensors}

Embedded system technology involves a making of small microcontrollers with low power, like the Microchip PIC micro MCU or DSPIC Digital Signal PIC Controller (DSCs). The combination of a microprocessor unit (like desktop PC with the CPU) with some other additional small circuits called "peripherals", and which makes a small control module with some of the additional circuits on the single chip then requiring few other external devices are called as microcontrollers. For the low-cost digital control some of the electronic devices and mechanical devices can be embedded into this single device. Also this microcontroller requires low power for its operation which is necessary for low power system designing.

A buzzer circuit can be interfaced with the receiver or master module along with the LCD display in order to alert the driver regarding the ups and downs in the pressure of each tire. The values are displayed in LCD monitor that indicates the real time values of the tire pressure monitoring system. When the tires pressure value gets exceed the predetermined values in any one of the tires, the buzzer circuit gets activated. Accordingly the driver can take the corrective action.

The transducer MP3V5050 series piezo-resistive sensor is designed for the wide range of applications when it uses a monolithic silicon pressure sensor, where it especially employing a microprocessor or microcontroller with A/D inputs. Figure 5 shows the diagram of pressure sensor. To provide an analog output signal as accurate and high level, that is proportional to the applied pressure, for advanced micromachining technologies uses single element transducers, a bipolar processing and thin-film metallization.

The main features of pressure sensor are $2.5 \%$ Maximum Error over $0^{\circ} \mathrm{C}$ to $85^{\circ} \mathrm{C}$. It was ideally matched for Microprocessor or Microcontroller-Based Systems. Its Temperature Compensated Over $-40^{\circ} \mathrm{C}$ to $+125^{\circ} \mathrm{C}$. Patented Silicon Shear Stress Strain

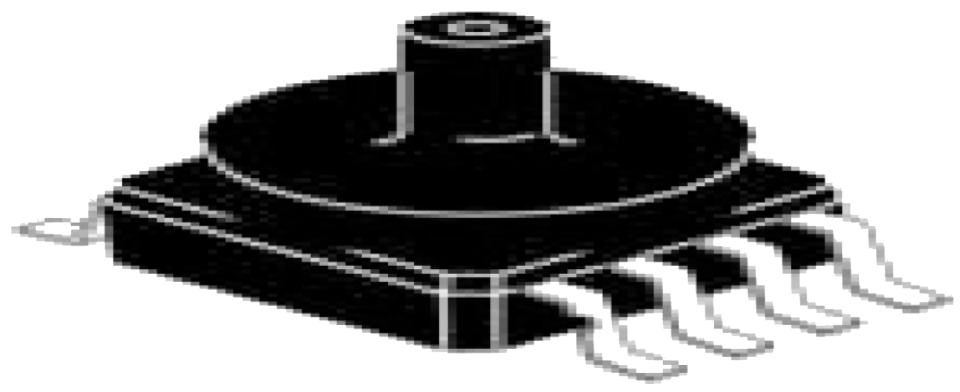

Figure 5. MP3V5050GC6U/6T1 case 482A-01 pressure sensor. 
Gauge, Thermoplastic (PPS) Surface is one of its main packages. For its design flexibility it uses porting options as multiple.

A precision integrated-circuit temperature sensors are belongs to LM35 series, where the Celsius (Centigrade) temperature is directly proportional to the voltage at output. Due to the advantage of LM35 over the linear temperature sensors calibrated in ${ }^{\circ} \mathrm{Kel}$ vin, then to obtain convenient Centigrade scaling there is no need to discard a large constant voltage from the voltage at the output.

To give the accuracy of $\pm 1 / 4^{\circ} \mathrm{C}$ at room temperature and $\pm 3 / 4^{\circ} \mathrm{C}$ over a full $-55^{\circ} \mathrm{C}$ to $+150^{\circ} \mathrm{C}$ temperature range, the LM35 sensor does not need any other calibration or trimming. Figure 6 shows the diagram of temperature sensor. In the level of wafer, we can achieve the low cost by doing the calibration and trimming.

To make interfacing to readout or control circuitry as easy, based on the output impedance the LM35's reading is taken, and then its reading is also based on precise inherent calibration and linear output. It can be used with positive or negative power supplies or with single power supplies. Because of its low self heating in still air that is less than $0.1^{\circ} \mathrm{C}$, it draws only $60 \mu \mathrm{A}$ from its supply. The LM35 is fixed to operate over a $-55^{\circ} \mathrm{C}$ to $+150^{\circ} \mathrm{C}$ temperature range, while the $\mathrm{LM} 35 \mathrm{C}$ is $-10^{\circ} \mathrm{C}$ with improved accuracy by rating with a $-40^{\circ} \mathrm{C}$ to $+110^{\circ} \mathrm{C}$ range. In LM35 series the LM35D are also available in plastic TO-92 transistor package and also it has the TO-46 transistor packages. The plastic TO-220 package and small outline package which are present in an 8-lead surface mount of LM35D.

The main features of pressure sensor are Calibrated directly in ${ }^{\circ}$ Celsius (Centigrade), Linear $+10.0 \mathrm{mV} /{ }^{\circ} \mathrm{C}$ scale factor $\& 0.5^{\circ} \mathrm{C}$ accuracy guarantee able $\left(\right.$ at $\left.+25^{\circ} \mathrm{C}\right)$. Rated for full $-55^{\circ} \mathrm{C}$ to $+150^{\circ} \mathrm{C}$ range and it is Suitable for remote applications. Due to wafer-level trimming its cost is low and also it operates from 4 to 30 volts with Less than $60 \mu \mathrm{A}$ current drain value, where $0.08^{\circ} \mathrm{C}$ low self-heating is measured in still air. Nonlinearity only will be $\pm 1 / 4^{\circ} \mathrm{C}$ typical. For $1 \mathrm{~mA}$, the load Low impedance output is 0.1 W.

The power consumption of the tire-pressure monitoring system components module has become a main reason for its performance because of battery-life requirements. To

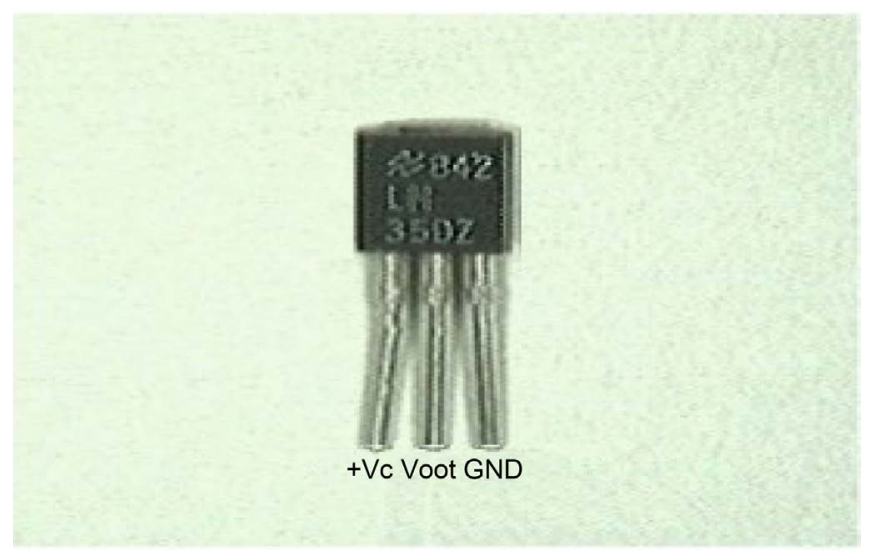

Figure 6. LM35 temperature sensor. 
obtain the lowest power consumption, presently, techniques such as sleep modes or standby mode along with duty cycling of the RF transmission are used. As of this part, the devices can be operated in two modes, namely "active" and "saturation" modes. When compared to the saturation mode, the movement of the car will accelerate into active mode by increasing the repetition rate up to 100 times pressure readings of TPMS application. RF transmission consumes more power than pressure measurement processing mode in the rate of 5\%. With the help of TPMS, Optimization can be done easily.

By reducing the frequent transmission of pressure measurement process also able to save power consumption. In some models, the sensor transmits the signals for an hour, when the vehicle are get parked, while other models are shut down the transmission that equipped with speed detectors. Once the sensor detects the trigger from the vehicles main processor it gets wake up and waits for the standby mode when sensor modules contain a low-frequency receiver integrated circuit.

\subsection{HC Serial Bluetooth}

HC serial Bluetooth products consist of Bluetooth adapter and Bluetooth serial interface module. In HC serial Bluetooth HC-04 slave mode is the default situation. In the case of need in master mode, directly place an order for HC-O4-M or state it clearly. The rule for naming HC-06 is same. To activate the device the parameters are to be set as one part, when the HC-03 and HC-05 are out of factory. The users can set the mode of HC-03, HC-05 because the work mode has not set. The connection diagram of Bluetooth is shown in Figure 7. The replacement of serial port line in Bluetooth serial module is one of the main and important functions, given as:

1) For the communication it uses two MCUs. In that two MCUs one is connected to slave device while the other one is connected to Bluetooth master device. Once the pair is made it can built their connections. This Bluetooth connection which gives the equally liked to a same serial port line connections including TXD, RXD signals. Bluetooth serial module is used to communicate with each other.

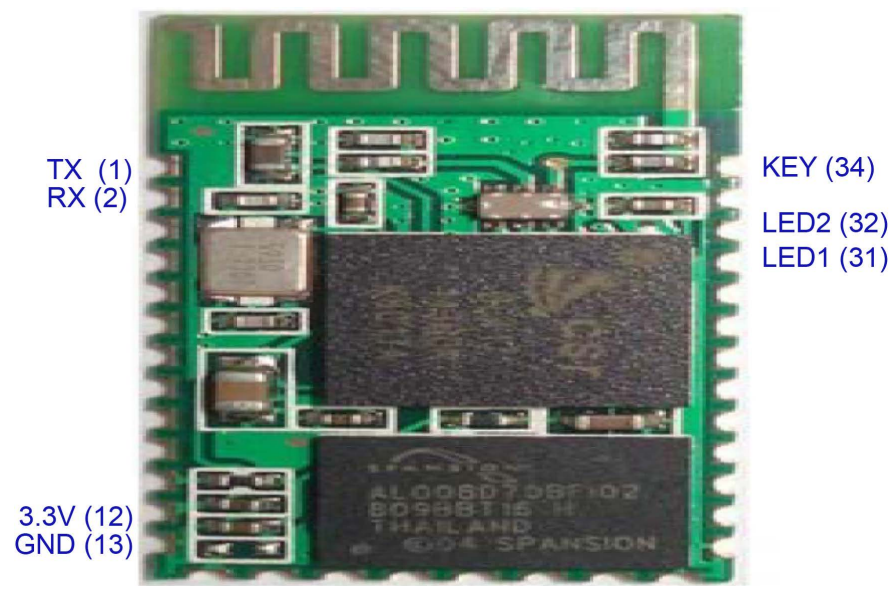

Figure 7. Connection diagram for Bluetooth. 
2) Bluetooth adapter of computers and smart phones can communicate with MCU, when MCU has Bluetooth slave module. Between the MCU and computer or smart phone, there is also an effect or virtual communicable serial port line.

3) In market Bluetooth devices are mostly slave devices, such as Bluetooth GPS, Bluetooth printer, etc. So, master module is used to make pair and communicate with them. Bluetooth Serial module's doesn't need drive for its operation, and also it can communicate with the other Bluetooth device that has the serial one. The following two conditions are required for the communication between two Bluetooth modules:

1) The master and slave must to be in communication.

2) Then the given password should be ideal.

However, the above two conditions are not only sufficient conditions. And also there is some other conditions based on the different types of device model.

To compatible with each other the Bluetooth serial module named as even number; thus the slave module is also consistent with each other. Where, the working of HC-04 and HC-06, HC-03 and HC-05 are equally compatible to each other. So the function mode (slave or master) can't be reset in the HC-04 and HC-06 former version.

To reset the password, first reset the user name of Bluetooth (by only the slaver), then reset the baud rate and then check the version number, are the few AT commands and functions used in selection of module. The HC-03 and HC-05 command set are more flexible than HC-04 and HC-06's. Generally, the users are recommended for Bluetooth of HC-03/HC-05.

\section{Software Description}

Proteus VSM needs a prior hardware prototype with the extensive debugging features, variable display, including breakpoints and single stepping for a neat design. The interaction between any digital or analog electronic device connected to microcontroller and software running on it, can be simulated by using the program of Proteus 7.0.

Figure 7 shows the MPLAB coding written and executed successfully. MPLAB is used to write the microcontroller coding. The coding written is loaded into the microcontroller that designed in PROTEUS software that has been shown in Figure 8.

For the simulation, the proteus is considered since it supports multiple streams of signal with microcontroller, such as 68,000 series, HC11 series, Z80 series, AVR series, PIC12 PIC16 series, 51 series, PIC18 series, etc. And provide software debugging function and its periphery connection device of memory element (like RAM, ROM), with keyboard and motor and also the display units (like LED, LCD) with the other devices like partial SPI, AD/DA. The technology with simulation in computers has become one of an important sector of many design method because of its development in the sector science.

It can make the design time as less or minimum, with low in cost and also risk of designing is got reduced for the engineers. Based on the microcontroller's application in PROTEUS it can also have extensive application. The pressure and temperature monitored, is the range that fixed in the program. If the temperature or pressure exceeds the 


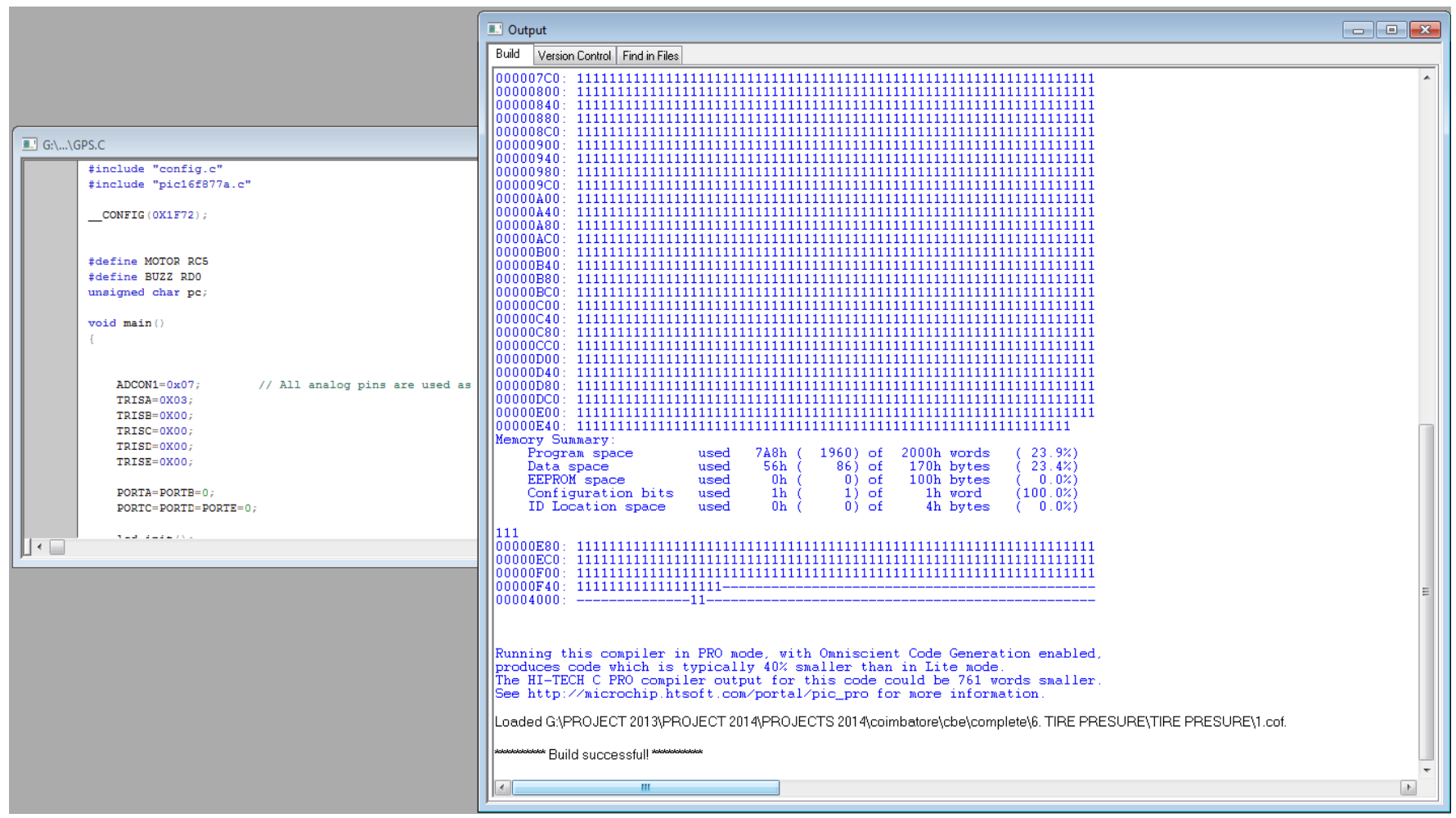

Figure 8. Coding written and executed in MPLAB.

fixed level then LCD display will displays the high temperature or high pressure. Then buzzer sound is indicated.

\section{System Performance Evaluation}

Analysis has been done through the simulation results with the help of proteus software and the improvement was shown through Figure 9. The pressure sensor MP3V5050GC6U will tolerate up to a maximum temperature of $85^{\circ} \mathrm{C}$ with the limitation of $2.5 \%$ error value. And we know that the temperature and pressure are relatively proportional to one another. Due to increase in temperature may lead the tire pressure to a saturation value. The relation between temperature and pressure are also shown in Figure 10 for better understanding. The devices which are utilized here need a maximum supply voltage of $5-12 \mathrm{~V}$, power consumption also as an added advantage (Figure 11 and Figure 12).

$$
\begin{gathered}
V_{\text {out }}=[P \pm E V](<25 \%) \\
P=[p \pm T]
\end{gathered}
$$

where,

$P=$ Pressure, $E V=$ Maximum Error Value, $p=$ partial pressure and $T=$ Temperature.

\section{Conclusions}

The implementation of a tire pressure monitoring system in combination with a very 


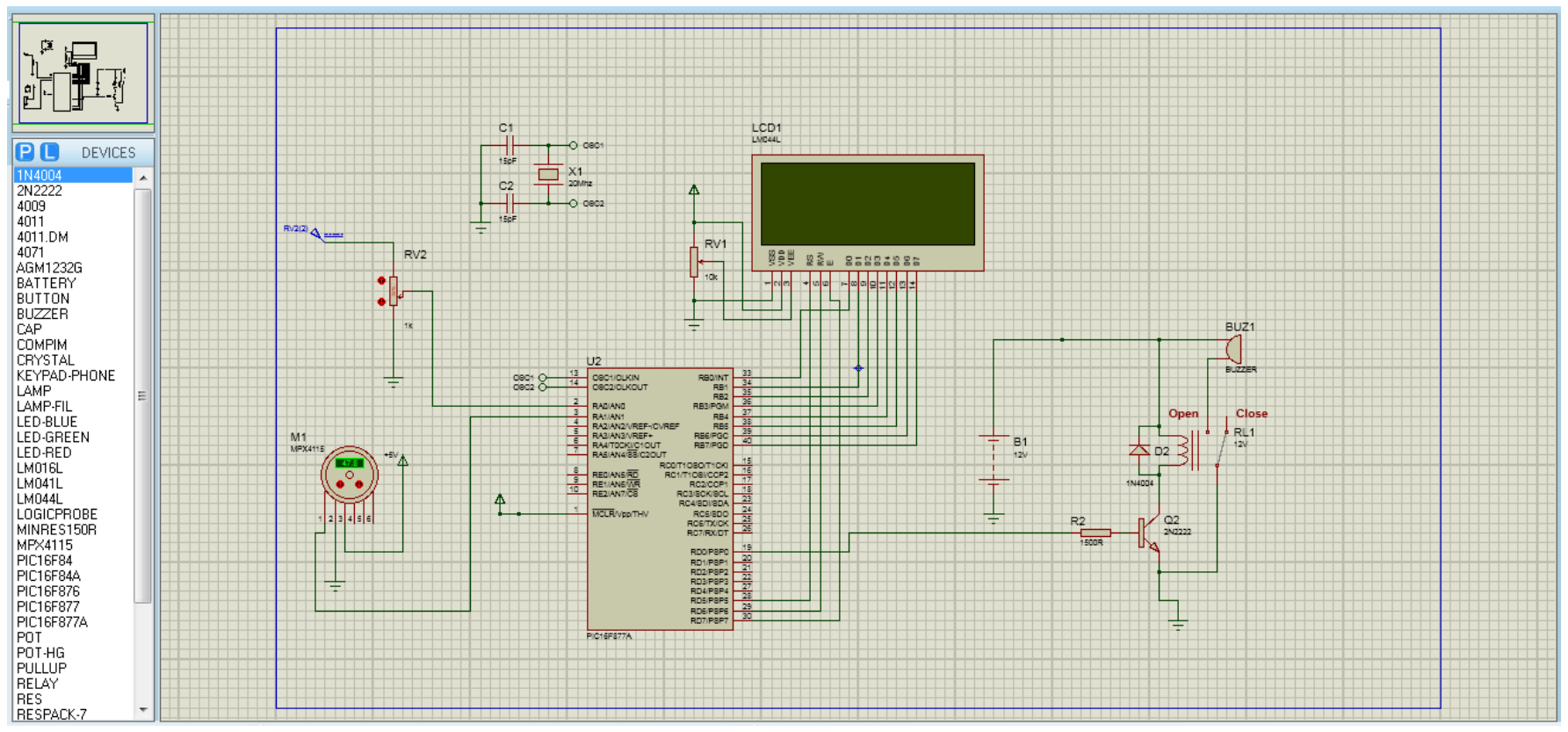

Figure 9. Designed project is selected into proteus software.

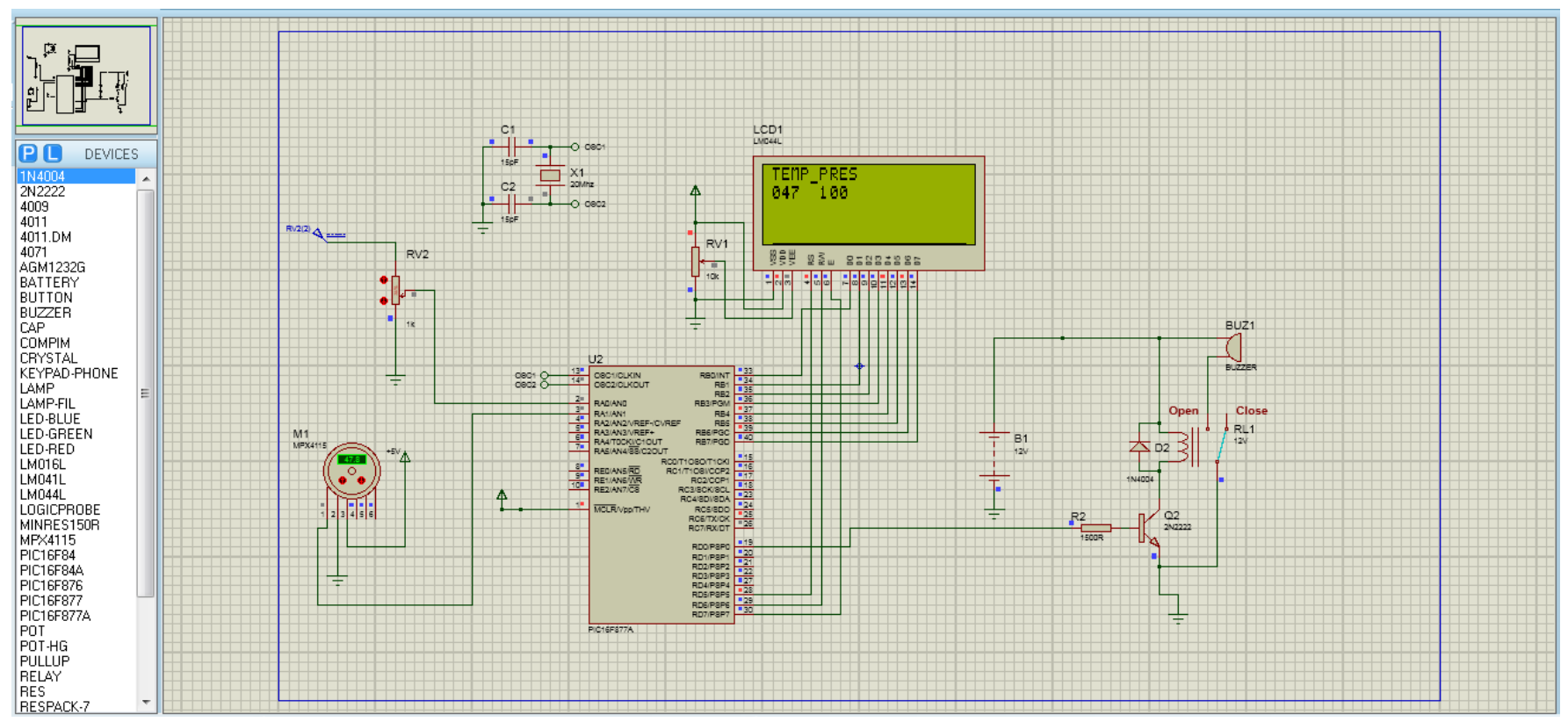

Figure 10. Output of tire pressure and temperature displayed in LCD.

low power design using SoC unit was proposed in this paper. The purpose of this idea is to increase the speed of indication time to monitor the signals from the tires, and also to reduce the power consumed by the sensors and other hardware components that are fixed inside the tires. Wireless Bluetooth technology that is used in this TPMS would definitely make it simpler than other complicated methods. For that, deep analysis has been taken and performance has been compared with the existing system, like existing system SPI interface and TPMS which works under high and low pressure in both type 


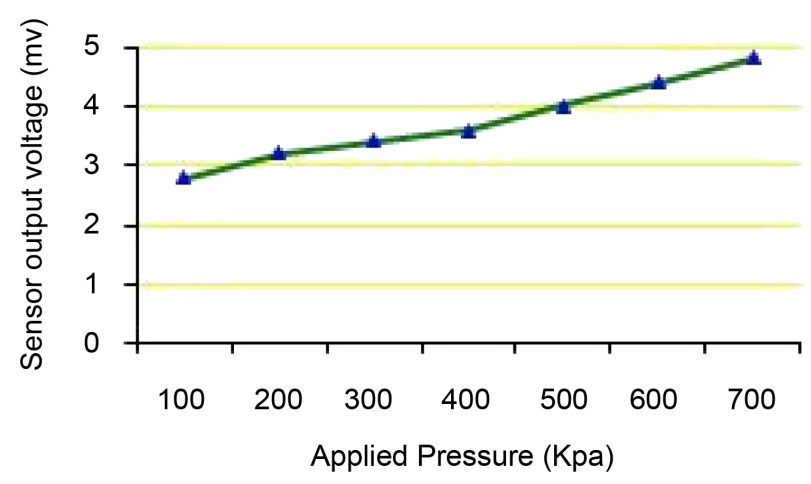

Figure 11. Applied pressure vs. output sensor voltage.

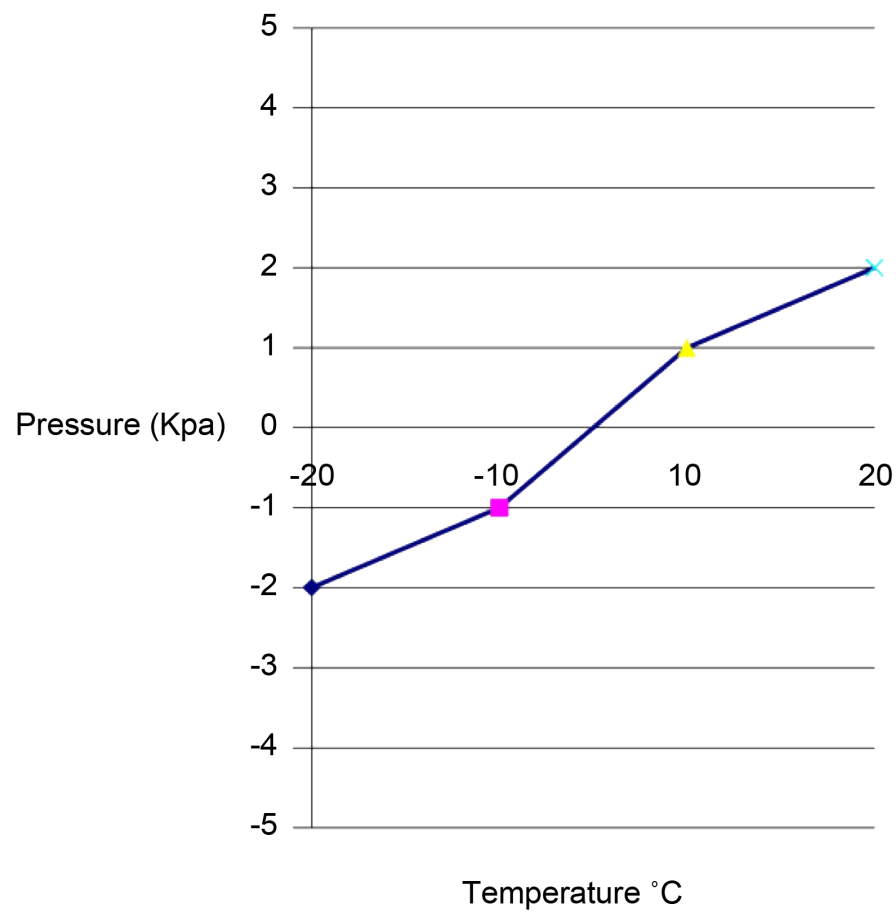

Figure 12. Outside temperature vs. pressure.

of situation.

In later years, TPMS will most likely be expected to incorporate new and more features owing to the increasing safety standards in automotive industry. This could be achieved in a number of ways like adding more sensors to the TPMS module in order to provide data other than pressure, temperature, wheel alignment, indication of puncture, load of the heavy vehicles, etc. or combining different information sources like the integration of TPMS communicating more effectively with other parts of the vehicle. Due to the non-replacement of the battery in TPMS, it can be proposed for more than two low power designs.

\section{References}

[1] Kale, A.D., Thakare, S.S. and Chaudhari, Dr.D.S. (2012) Wireless Tire Pressure Monitoring 
System for Vehicles Using SPI Protocol. International Journal of Advance Research in Computer Engineering \& Technology, 1, 89-91.

[2] Shao, M. and Guo, W. Tire Pressure Monitoring System. 978-1-4244-9439-2/11.

[3] Christensen, C. and Branquart, H. (2008) Wireless with ASIC Enable Tire Pressure Monitoring System. EE Times Asia Mag., September.

[4] Mnif, K. (2001) A Smart Tire Pressure Monitoring System. Sensors Mag., Nov 1.

[5] Balaji, K., Madhav, B.T.P., Syam Sundar, P. and Rakesh Kumar, P. (2011) Tyre Pressure Monitoring and Communicating Antenna in the Vehicular Systems. International Journal of Advances in Engineering \& Technology, 1, 422-428.

[6] Langley, R.J. and Batchelor, J.C. (2004) Hidden Antennas for Vehicles. Electronics \& Communication Engineering Journal, 14.

[7] Liu, Y.M., Huang, B.H., Shen, J.C. and Yuan, Y. (2010) Design and Implementation of TPMS Based on the Wireless Sensor Network. International Conference on Intelligent System Design and Engineering Application, 13-14 October 2010, 518-523. http://dx.doi.org/10.1109/ISDEA.2010.436

[8] Zhang, J., Liu, Q. and Zhong, Y. (2008) A Tire Pressure Monitoring System Based on Wireless Sensor Networks Technology. International Conference on Multi Media and Information Technology, 30-31 December 2008. http://dx.doi.org/10.1109/MMIT.2008.177

[9] Fleming, B. (2009) Tire Pressure-Monitoring Systems Using Rollout. IEEE Vehicular of the Technology, May.

[10] Yu, S.M., Tang, J.B., Qiu, H. and Cao, C.R. Wireless Communication Based Tire Pressure Monitoring System. 1-4244-1312-5/07.

[11] Wang, Z.X., Xu, Y. and Wang, G.J. Design and Implementation of Tire Monitoring System Based on Zigbee. 978-1-4244-09, pp. 89-91.

[12] Burrer, C. (2004) Direct Measuring Tire Pressure Monitoring Systems. VDI Berichte, 1829, 517-521, 913.

[13] (2006) Tire Pressure Monitoring System. Agilent TS -5020 Application Note, Dec 11, 06, pp. 14.

Submit or recommend next manuscript to SCIRP and we will provide best service for you:

Accepting pre-submission inquiries through Email, Facebook, LinkedIn, Twitter, etc. A wide selection of journals (inclusive of 9 subjects, more than 200 journals)

Providing 24-hour high-quality service

User-friendly online submission system

Fair and swift peer-review system

Efficient typesetting and proofreading procedure

Display of the result of downloads and visits, as well as the number of cited articles

Maximum dissemination of your research work

Submit your manuscript at: http://papersubmission.scirp.org/

Or contact cs@scirp.org 